\title{
sciendo
}

Folia Oeconomica Stetinensia

Volume 20 (2020) Issue 1

DOI: $10.2478 /$ foli-2020-0008
WYDZIAL NAUK EKONOMICZNYCH I ZARZA_DZANIA

\section{UNRAVELLING THE SECRETS OF INFLATION IN THE EURO AREA - A FREQUENCY DECOMPOSITION APPROACH}

\author{
Prof. Dieter Gerdesmeier \\ European Central Bank \\ Sonnemannstrasse 20, 60314 Frankfurt am Main, Germany \\ e-mail: diet-er.gerdesmeier@ecb.europa.eu \\ ORCID: 0000-0002-4428-0660 \\ Barbara Roffia, Ph.D. \\ European Central Bank \\ Sonnemannstrasse 20, 60314 Frankfurt am Main, Germany \\ e-mail: barbara.roffia@ecb.europa.eu \\ ORCID: 0000-0002-0273-7642
}

\section{Prof. Hans-Eggert Reimers}

Hochschule Wismar

Postfach 1210, 23952 Wismar, Germany

e-mail:Hans-Eggert.Reimers@hs-wismar.de

ORCID: 0000-0001-6126-2037

Received 21 January 2020, Accepted 9 March 2020

\begin{abstract}
Research background: The study contributes to the field of monetary economics. In the practice of monetary policy, all central banks have a vivid interest in distinguishing between signals and noise in the data.

Purpose: The study investigates from a frequency-domain perspective the interlinkages between money, loans, inflation and real GDP for the euro area.

Research methodology: The research methodology includes a combination of a time-series single-equation estimation approach with a frequency decomposition analysis.

Results: Broad monetary measures are found to add positively and significantly to euro area inflation over longer horizons and so do loan developments. Over medium-term horizons, real economic and exchange rate developments seem to exert a significant impact. Over shorter horizons, none of the variables under consideration affects inflation in a significant way. Robustness checks confirm the overall results. Monetary aggregates also seem to explain house price developments at lower frequencies. In addition, real GDP and exchange rate (possibly reflecting an income effect) exert a strong and significant impact, while stock prices show a substitution effect.
\end{abstract}


Novelty: The paper adds to the studies focusing on the driving forces of inflation and growth over various time horizons, with the conclusion that central banks should adopt medium-term orientation and always closely monitor real, monetary and exchange rate developments in conjunction.

Keywords: Frequency decomposition, inflation, money, credit

JEL classification: E31, E52

\section{Introduction}

The role of money and credit for the economy, and especially for inflation, has always attracted a lot of attention in the economic literature (see, for instance, Friedman, Schwartz, 1963; Bernanke, 1993; and, more recently, Nelson, 2008; Benati, 2009; Lucas, Nicolini, 2015; Hevia, Nicolini, 2017; as well as Anderson, Bordo, Duca, 2017). This paper addresses some key questions regarding the fundamental nature of the relationships among those variables and attempts to analyse them for the euro area by means of filter-design techniques. After decomposing the variables over different frequencies, regressions are carried out and the main drivers of inflation over different horizons are derived in a single-equation approach. Robustness checks are also carried out by choosing different combinations of explanatory variables, price measures (GDP deflator and house prices) and across different frequency horizons.

The paper is structured as follows. After a review of the literature and methodology, the basic framework as well as the relevant variables used in the analysis are illustrated in more detail. Afterwards, the results for the HICP, the GDP deflator and house prices at different frequencies are provided. The final section concludes by summarising the main results.

\section{Review of the literature and methodology}

The interplay of longer-term trends and business cycle momentum has always been a very important topic of interest for economists. The related literature is vast and a variety of approaches have been used. Among the most popular approaches are spectral analysis, loglinear trends, correlation analysis, best fitting polynomial regressions, filter design approaches, structural time series models, fractional integrated long memory processes, outlier identification and trend breaks with stochastic models (see Gallegati et al., 2017) and the literature review therein). Among these methods, spectral analysis and filter design techniques clearly stand out. 
Ever since the earlier seminal articles (see for instance Engle, 1974), it is a well-known fact that most (if not all) economic processes can be seen as the result of a combination of various components operating on different frequencies or, equivalently, in different spectrums. ${ }^{1}$ Indeed, the theory of spectral analysis provides a rigorous framework for extracting specific frequency bands from the data, with the major limitation consisting of the fact that the stationarity of the observed time series is a basic requirement for this method to be applied.

However, this precondition does not have to be met in case a filter-design approach is used. Similarly to the spectral analysis, the filter-design approach regards a time series as the outcome of the interplay of various frequencies and the filter coefficients allow to isolate the various frequencies and, thus, the frequency components in the time domain. In the literature, this has initiated the development of a number of band-pass filters with the ones suggested by M. Baxter and R.G. King (1999) and L.J. Christiano and T.J. Fitzgerald (2003) probably being two of the most popular ones.

Technically speaking, band-pass filters remove both low and high frequencies from the time series. In the case of the filter proposed by M. Baxter and R.G. King (1999) for instance, the business cycle component is isolated by applying a moving average to the time series under consideration.

In essence, the method relies on the use of a symmetric moving average to a time series $y_{t}:^{2}$

$$
y_{t} *=\sum_{h=-K}^{K} a_{h} y_{t-h}=a_{0} y_{t}+\sum_{h=1}^{K} a_{h}\left(y_{t-h}+y_{t+h}\right)
$$

where $K$ denotes the number of leads and lags. Starting from the Cramer representation of a zero mean stationary time series $y_{t}$, i.e.:

$$
y_{t}=\int_{-\pi}^{\pi} \xi(\omega) d \omega
$$

which expresses the time series as the integral of random periodic components $\xi(\omega)$, it can be shown that the filtered time series can then be expressed in the following form:

$$
y_{t}^{*}=\int_{-\pi}^{\pi} a(\omega) \xi(\omega) d \omega
$$

\footnotetext{
${ }^{1}$ Seen from that perspective, several issues lead to a closer understanding of the behaviour of time series at different frequencies. In the older literature, mostly the so-called "Fourier analysis" was used to study the cyclical nature of a timeseries in the frequency domain. This, however, had a major disadvantages in that, under the Fourier transformation, the time dimension of the series got (at least partly) lost.

2 See Baxter and King (1999, p. 576 ff).
} 
where the $a(\omega)$ denote the frequency response function of the linear filter. The variance of the filtered series can be summarised by the following expression:

$$
\operatorname{var}\left(y_{t}^{*}\right)=\int_{-\pi}^{\pi}|a(\omega)|^{2} f_{y}(\omega) d \omega
$$

where $|a(\omega)|^{2}$ is the squared gain of the linear filter at frequency $\omega$ and $f_{y}(\omega)$ is the spectral density of the original series at frequency $\omega$.

The Baxter-King filter is known to have a number of desirable properties. To begin with, it can be shown that the filter does not introduce any phase shift into the data. Second, the filter is able to render a stationary time series as an outcome. Third, the filter is insensitive to the presence of deterministic trends in the data. This notwithstanding, applying the filter to a time series is equivalent to losing $K$ observations at the beginning and at the end of the series, hence necessitating a careful choice of the maximum lag length.

\section{Economic framework}

The general model underlying this study can be specified as follows: ${ }^{3}$

$$
\operatorname{dev}(p)_{t}{ }^{f}=\alpha_{0}+\alpha_{1} \operatorname{dev}(m)_{t-1}{ }^{f}+\alpha_{2} \operatorname{dev}(y)_{t-1}{ }^{f}+\alpha_{3} \operatorname{dev}(x)_{t-1}{ }^{f}+\varepsilon_{t}
$$

where $t$ stands for the time index and $f$ denotes the frequency band. As regards the variables, $p$ denotes prices, $m$ and $y$ represent a measure of the monetary aggregate and economic activity, respectively, and $x$ stands for a control variable. Moreover, the expression dev denotes the deviation from the respective sample mean (of the annual growth rates).

The choice of selecting monetary aggregates and real economic variables (including GDP) is justified on the basis of the ECB's monetary policy strategy (see ECB, 1998, 1999a,b, 2003) as well as by earlier work (see, for instance, Gerlach, Svensson, 2003). Other variables used in the analysis are meant to reflect the fact that the euro area represents an open economy. ${ }^{4}$

In the analysis presented in this paper, the following variables for the euro area are used: $p$ denotes the harmonised index of consumer prices (HICP) or, alternatively, other price measures, such as the GDP deflator and house prices. ${ }^{5}$ The symbol $m$ stands for the different monetary aggregates (M1, M2, M3 and loans to the private sector). The abbreviation $y$

\footnotetext{
3 See Andersson (2008, 2011).

4 In this respect, exchange rate measures, stock prices and oil prices are considered.

${ }^{5}$ For more details regarding the source of the variables used in the analysis, see Annex 2 in Gerdesmeier, Reimers and Roffia (2018).
} 
represents three alternative measures, namely, either the output gap, real GDP or, alternatively, the unemployment rate. Finally, $x$ denotes the euro exchange rate vis-à-vis the US dollar (or the nominal (effective) exchange rate of the euro) or, alternatively, oil prices. ${ }^{6}$ The data sample covers the period from 1980 Q1 up to 2017 Q2.

For all variables, a filter-design exercise is carried out to take explicitly into account the fact that the effects of the variables might unfold over different frequencies. ${ }^{8}$ In line with K. Assenmacher-Wesche and S. Gerlach (2007), F.N.G. Andersson (2008, 2011), L. Benati (2009) and A.A. Haug and W.G. Dewald (2012), we decompose developments in euro area consumer inflation into three time horizons, namely the short run (up to two years), the medium run (two to eight years) and the long run (eight years and beyond) using a variant of a Baxter-King filter. ${ }^{9}$ We then regress the inflation variables on the set of variables mentioned above. In order to check our results for robustness, we run the estimations by using different combinations of monetary and real variables.

From a technical perspective, the estimations are carried out for the euro area by means of the GMM-estimation technique (Hansen, 1982). The latter choice is justified by the need to correct for possible simultaneity issues.

\section{Results}

A simple graphical illustration of the technique outlined above starts from the decomposition of observed inflation over the past three decades into three main components, i.e. the "longrun frequency" component (i.e. those movements in inflation with a periodicity of more than 8 years); the "business cycle frequency" component (defined as movements with a periodicity of more than 2 years, but less than 8 years) and the "irregular frequency" component (defined as movements with a periodicity of less than 2 years).

A graphical representation of the relation between euro area HICP inflation and M3 growth is provided in Figure 1. The chart reveals that developments in the low frequency component of euro area inflation tend to mirror actual M3 developments quite closely and in a rather smooth fashion. Only between 2005 and 2006 and from 2010 onwards a slight decoupling of the two

\footnotetext{
${ }^{6}$ Moreover, euro area stock prices are included in the analysis in order to test for a possible role in the monetary policy transmission mechanism.

${ }^{7}$ However, due to the filtering procedures, some observations are lost at the beginning and at the end of the sample (as it can be evinced in the results shown in the charts).

${ }^{8}$ The only exception is the output gap, which is not decomposed but kept unchanged in all specifications.

9 As a cross-check, the analysis was also carried out using the Christiano-Fitzgerald filter. The results are available from the authors upon request.
} 
a) long-run frequency

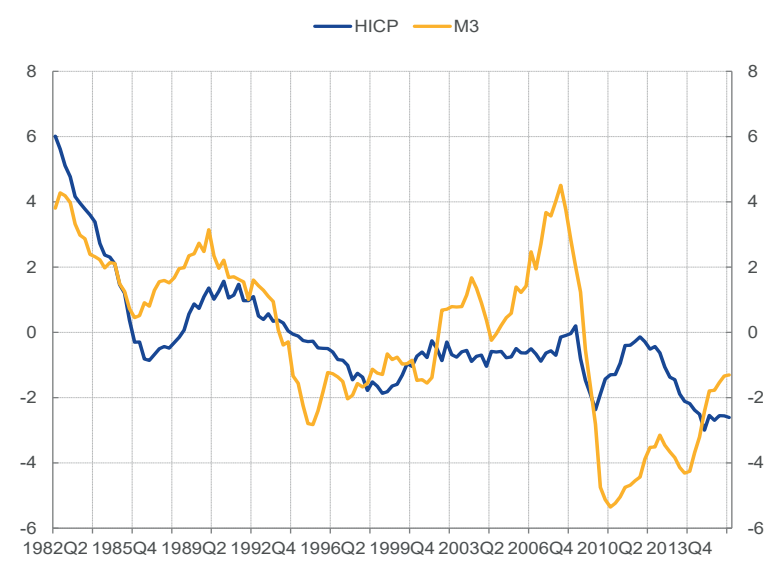

b) business cycle frequency

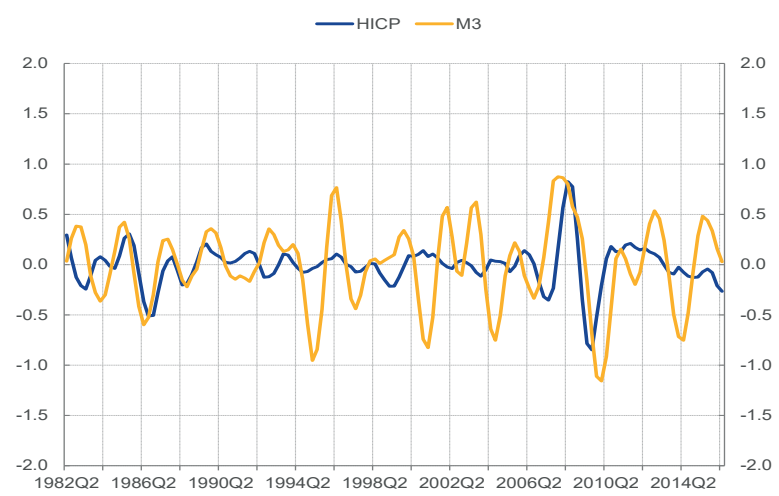

c) irregular frequency

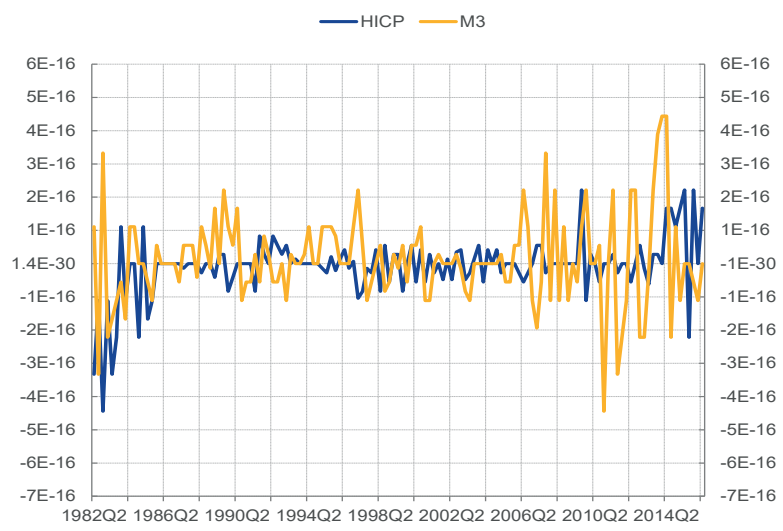

Note: money (M3) and HICP, both measured as (demeaned) annual growth rates.

Figure 1. HICP and M3 developments at different frequencies

Source: own estimations. 
series can be detected. By contrast, the business cycle component tends to swing considerably around the zero line, thereby illustrating in an impressive way the effects that business cycles may have on price developments. Finally, the irregular component follows a very volatile pattern.

In order to derive the fundamentals prevailing in the euro area at the current stage, we start our analysis by estimating the aforementioned specification for the euro area based on a sample spanning the period from 1980 Q1 to 2017 Q2. The tables in Annex show the results of the inflation equation for the different frequencies. For each block of the tables the regressions differ because of the monetary aggregates used (M1, M2, M3 and loans). The same applies for the real variables and the control variables.

The interpretation of the results for the HICP at the long-term horizon leads to the following conclusions. First, starting with the first part of Table 1, we find that the broader monetary measures (namely M2 and M3) add positively and significantly to inflation over longer horizons and so do loan developments. The narrow monetary aggregate M1 generally shows a negative sign (albeit not significant in almost all specifications), a result which is consistent with the predominant nature of M1 as a transaction variable. Real economic developments (as measured by the output gap) do not provide additional information, whereas the euro exchange rate visà-vis the US dollar seems to have a significant (negative) influence. In addition, when turning to the other parts of the table, the same results seem to hold in case real GDP growth is used instead of the output gap. At the same time, also a higher low frequency unemployment rate has a negative influence on inflation (see column III of the table). Omitting the exchange rate or adding stock or oil prices do not seem to improve the results in any substantial way (with one exception, where the interplay between loans, real GDP and stocks seems to lead to significant results). ${ }^{10}$ It is also worth noting that the explanatory power is best over the longer-term horizon (not shown separately).

Over the medium term (see Table 2), positive and significant effects from real developments (shown in both the output gap and real GDP growth) emerge, as could be expected on the basis of Phillips curve considerations. Moreover, the exchange rate continues to exert a negative and significant influence also over the business cycle (albeit much weaker than over the long-term horizon). Finally, in some specifications, broader monetary aggregates developments and loan developments still contribute to explaining inflationary developments, albeit to a much lesser extent (as mirrored in the size of the respective coefficient).

10 Stock prices are significant, but the size of the coefficient seems rather small. 
Over shorter horizons (see Table 3), the results seem to indicate that none of the variables under consideration affects consumer inflation in a significant way and, thus, fluctuations in consumer inflation that last up to two years are either noise, or may be explained by past values or seasonal effects.

To sum up, it is interesting to note that, as the frequency increases, the role and importance of fundamentals in explaining inflation developments come to the fore. In particular, the results point to a close monitoring of monetary developments over longer horizons. By contrast, over short- to medium-term horizons, the output gap and the exchange rate (and, occasionally, monetary aggregates) seem to be of more relevance. In line with other studies, we tend to interpret the results as lending support in favour of the ECB's two-pillar monetary policy strategy (see Andersen, 2007).

A number of robustness checks of these results were also carried out. First, we replaced the euro/dollar exchange rate with the nominal effective exchange rate. Overall, small differences can be detected, the only exception consisting of the fact that, at the lower frequency horizon, the exchange rate coefficients turn out to be less significant (see Tables 4 and 5).

The second robustness check consisted in re-estimating the equations by using the GDP deflator to derive the measure of inflation (see Tables 6 and 7). In this case, the results for the monetary aggregates over the low frequency horizon continue to hold, but the results for the exchange rate turn out to be less significant. We attribute this to the fact that - by contrast to the GDP deflator - the HICP includes more items that are directly influenced by movements in the exchange rate. Turning to the business cycle frequency, real developments do not seem to play a role anymore.

Finally, we carried out an additional exercise based on a redefinition of the low and medium-run frequency horizon. More concretely, we now define the long run as a horizon exceeding 16 years, while the medium run comprises a period between 2 and 16 years (see Tables 8 and 9). ${ }^{11}$ The results again show that the broader monetary measures (M2 and M3) and loans add positively and significantly to inflation over longer horizons. Real developments (as measured by the output gap) have no explanatory power, whereas the exchange rate seems to have a significant influence. Over the business cycle, real developments seem to better explain inflationary developments, supported by a significant contribution of developments in the exchange rate and oil prices.

\footnotetext{
11 The results can be found in Annex A in Gerdesmeier, Reimers and Roffia (2018).
} 


\section{An extension to house prices}

The present study is extended by analysing the driving forces of developments in house prices at different frequencies. The focus on house prices is justified on the basis of their importance both from a monetary policy perspective and also for financial stability considerations related to their interlinkages with monetary policy and real economic developments (see Nocera, Roma, 2017; Moulton, Wentland, 2017; IMF, 2018 ${ }^{12}$ ). In fact, real estate property must be seen as the most important component of household wealth, and housing expenditures essentially constitute a major part of households' financial budgets, thus being linked to households' consumption and savings behaviour and, ultimately, to consumer prices. Furthermore, a high level of money holdings might signal a large amount of liquidity being invested in potentially higher-yielding opportunities, which could fuel a bubble once a trend has been triggered and herding behaviour sets in. This is why rapidly rising house prices are often associated with an easing of credit conditions, increased spending and, ultimately, inflationary pressures.

In this context, money and credit play an important role. A vast literature illustrating the leading indicator property of money and credit for asset prices as well as the interaction between credit and asset prices (e.g. via banks' leverage ratios and the financial accelerator) has been produced over the years (see, for instance, ECB, 2010; Gerdesmeier et al., 2016 and all the references therein).

Compared to consumer prices, the role of house prices can set in already at an earlier stage of the transmission mechanism. In this respect, house prices might be subject to a variety of partly reinforcing and partly contradicting, effects, such as income effects, substitution effects and other direct and indirect effects.

Turning to the results (see Tables 8 and 9), at the lower frequency all monetary aggregates (including loans) seem to exhibit a sizable and significant effect, with the expected positive sign. While the output gap does not show any remarkable effect, real GDP exerts a strong and significant impact in all specifications. The strong and positive effect of the exchange rate can be explained by an income effect. An appreciation of the euro exchange rate is equivalent to cheaper imports and, thus, more purchasing power available for spending, which could drive house prices up. Stock prices seem to show a substitution effect. No impact of oil prices on house prices can be detected at the lower frequency.

\footnotetext{
12 See especially Chapter 3.
} 


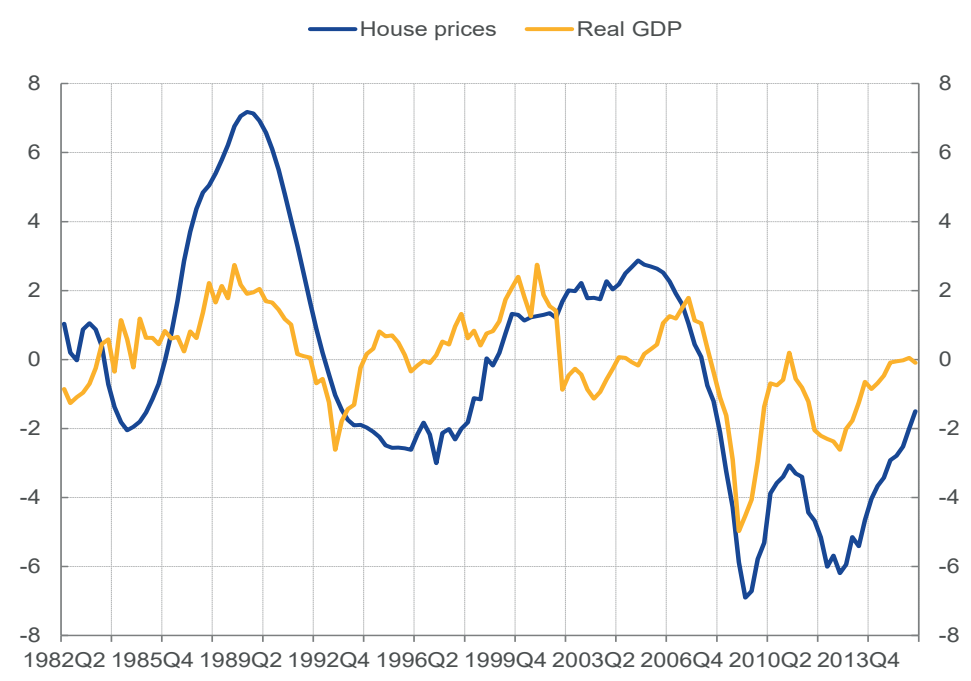

Note: low frequency real GDP and house prices, both measured as (demeaned) annual growth rates.

Figure 2. House prices and real GDP developments at the long-run frequency Source: own estimations.

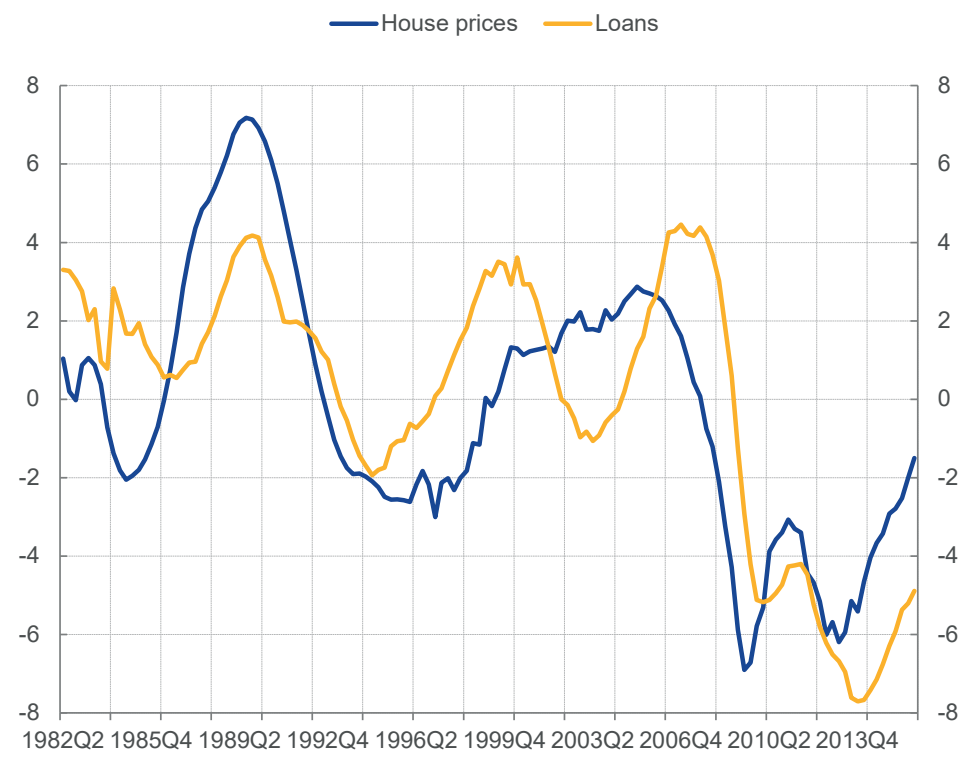

Note: low frequency loans to the private sector and house prices, both measured as (demeaned) annual growth rates.

Figure 3. House prices and loan developments at the long-run frequency

Source: own estimations. 
As for the business cycle frequency, mainly real developments seem to dominate house prices, whereas exchange rates show no significant impact.

A graphical representation of house price developments and real GDP and loans at low frequency shows that they tend to co-move closely, also over the most recent period (see Figures 2 and 3).

\section{Conclusions}

The analysis carried out in this paper suggests that, within a single-equation framework, the interlinkages between, money, loans, inflation and real GDP vary across frequency. As the frequency increases, the monetary and credit fundamentals come to the fore. An application of the same techniques to house prices also shows the close interrelation of loans and house prices developments at the lower frequency. In our view, these results corroborates the medium-term orientation to be followed by the monetary authority, but also for a constant and close monitoring of real, monetary developments and exchange rate developments. This notwithstanding, the results should not be interpreted as if, over shorter horizons, it would not be necessary to carefully monitor and analyse economic data. In this respect, it has to be kept in mind that, at any point in time, the actual data are composed of signals convoluted over different frequencies.

An encompassing analysis of all variables under review at any point in time is needed and recommendable. Of course, a more detailed analysis of the interplay of leads and lags and of the causalities of all factors could be of interest for future research. ${ }^{13}$

\section{Disclaimer}

The paper does not necessarily reflect the views of either the European Central Bank or the Frankfurt School of Finance and Management or the Hochschule Wismar.

\footnotetext{
${ }^{13}$ It might, for instance, be considered to replace the single-equation framework with a VAR-type analysis.
} 


\section{Annex}

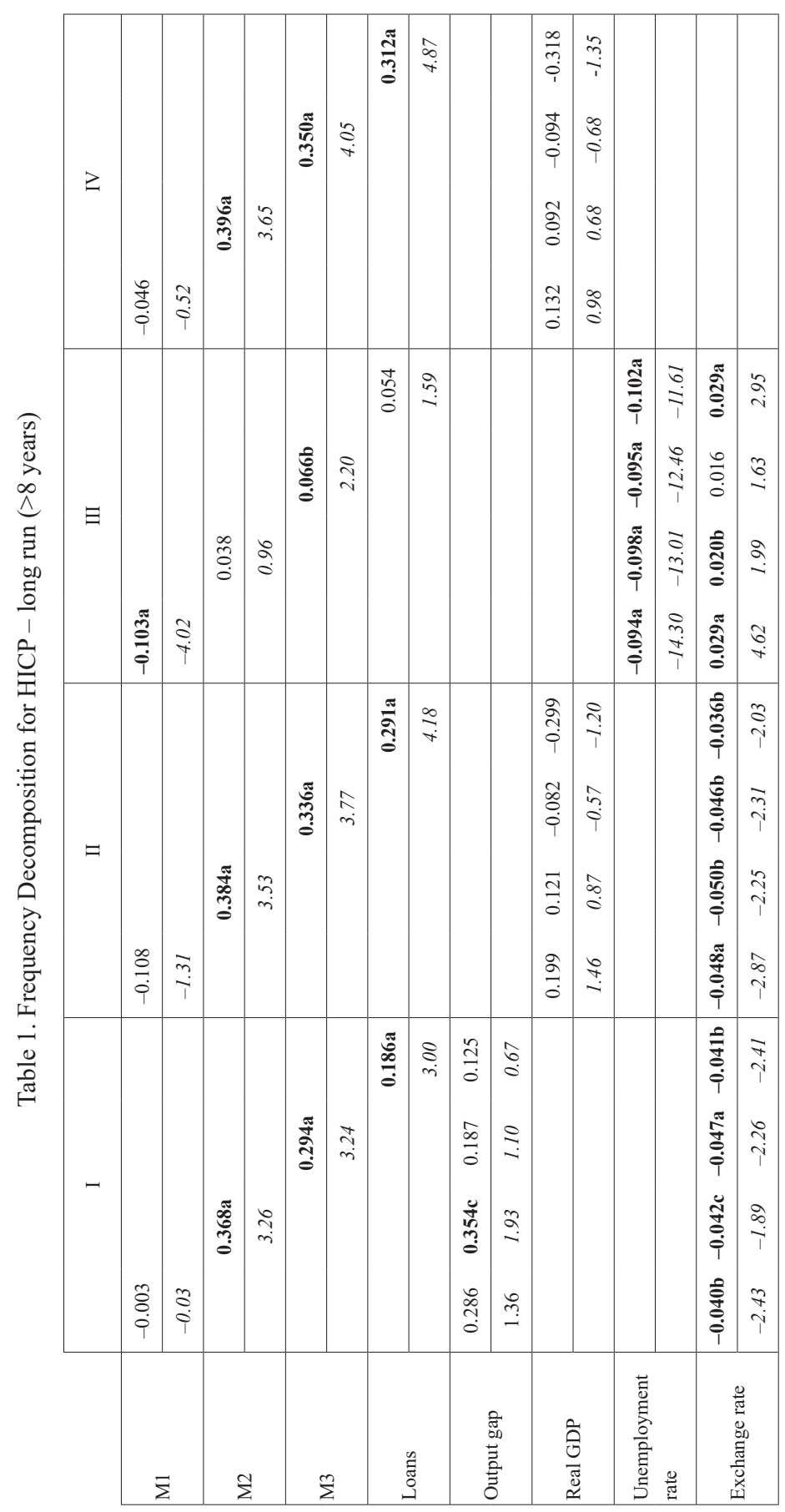




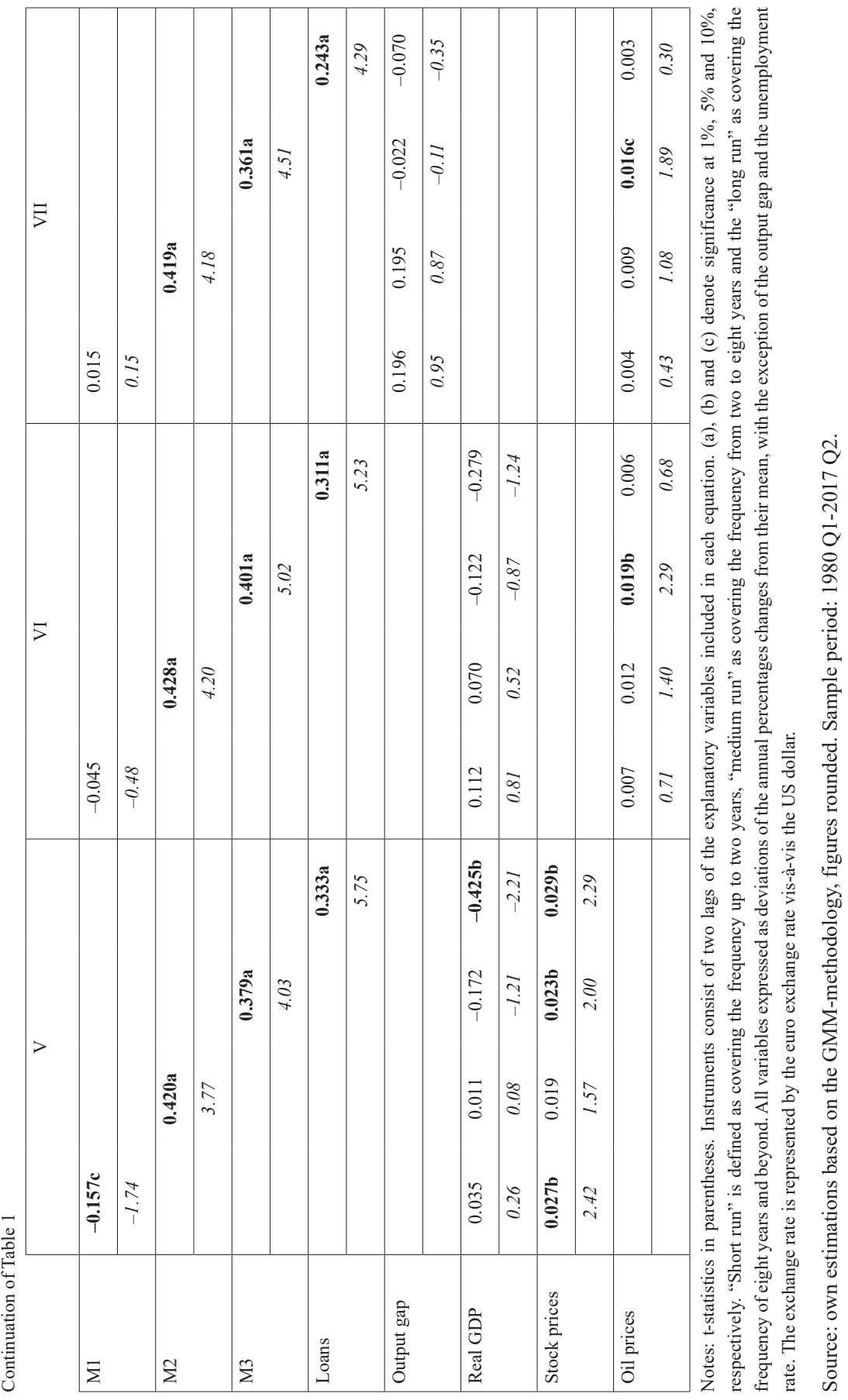




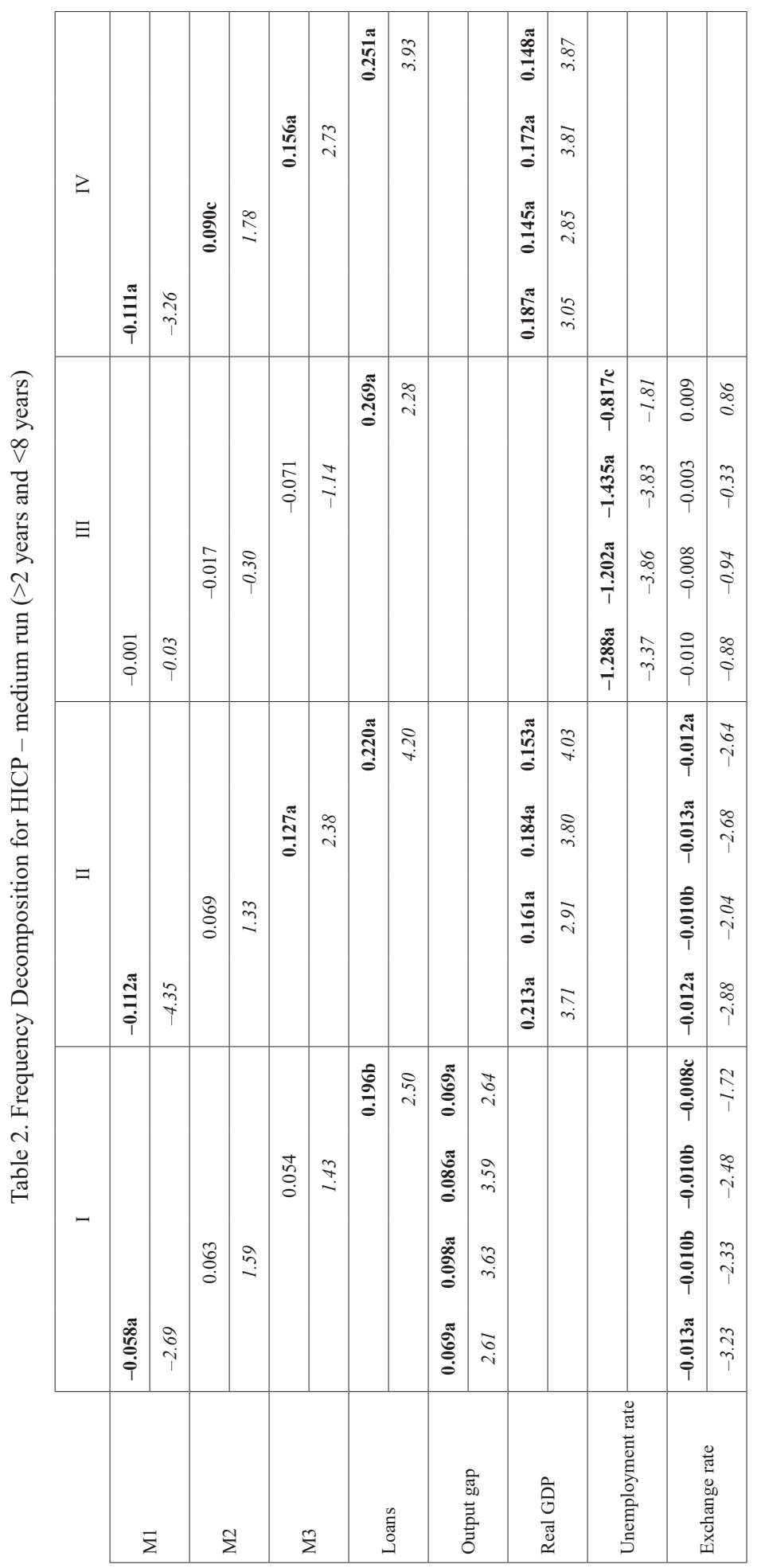




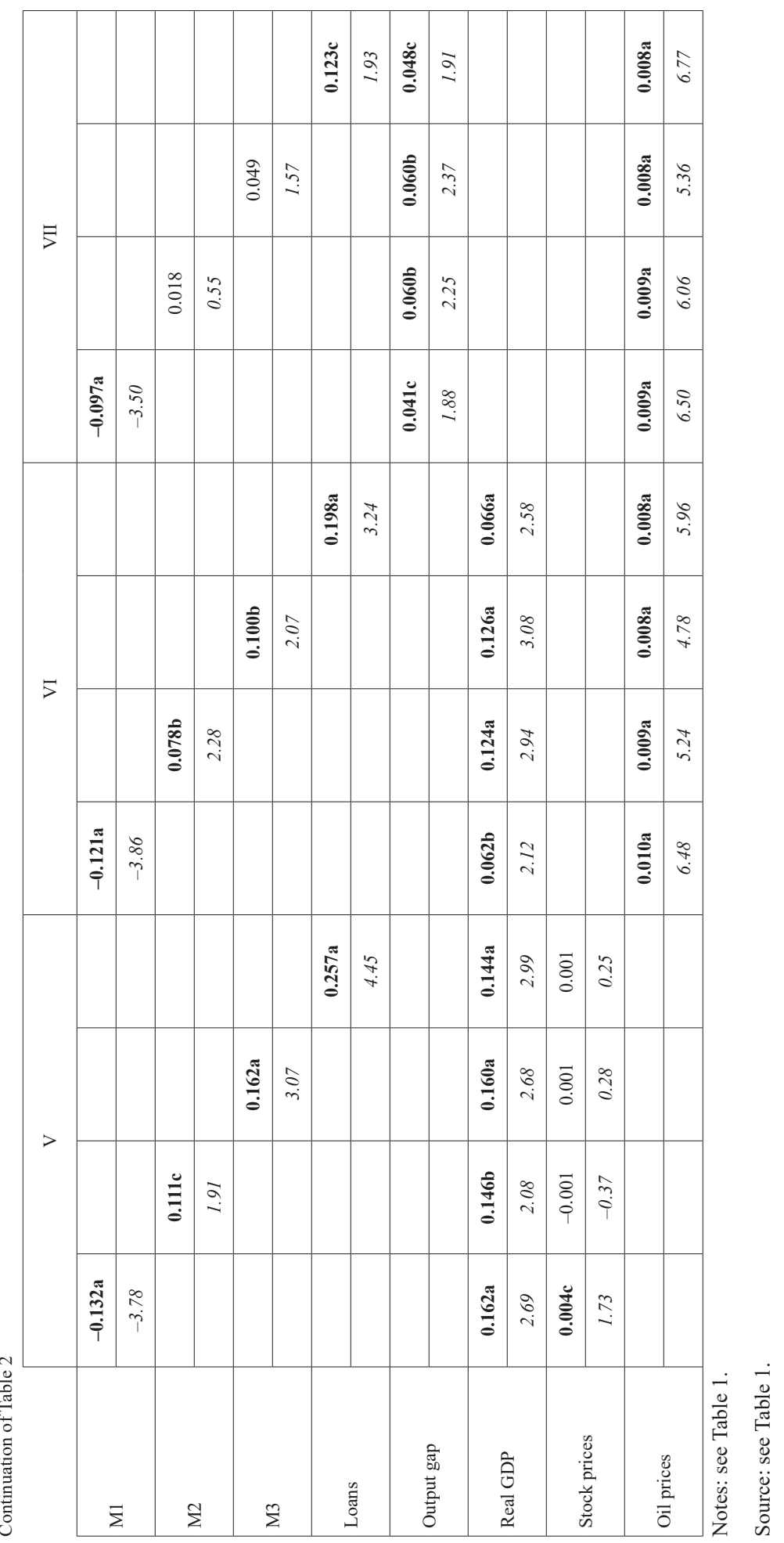




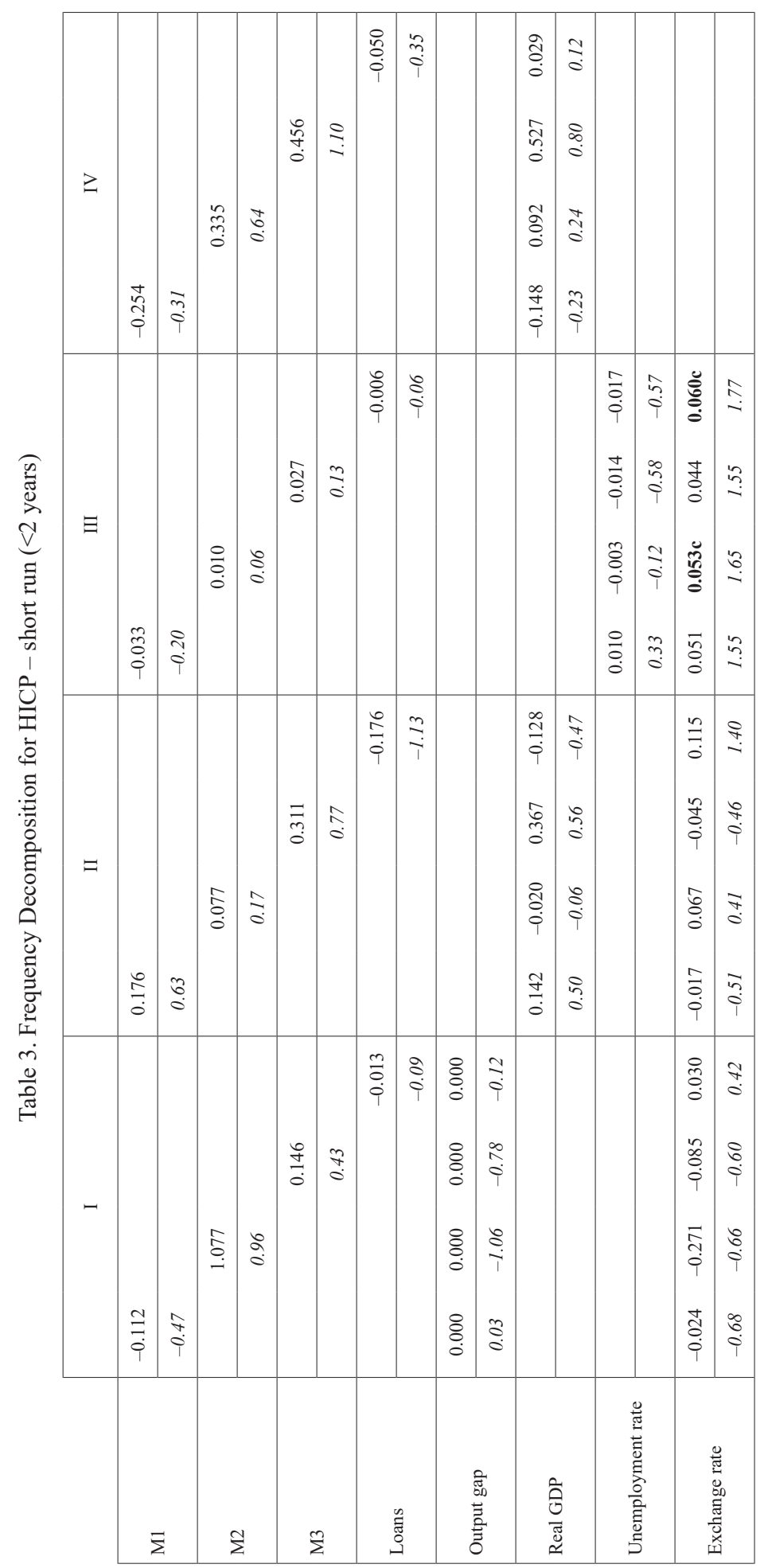




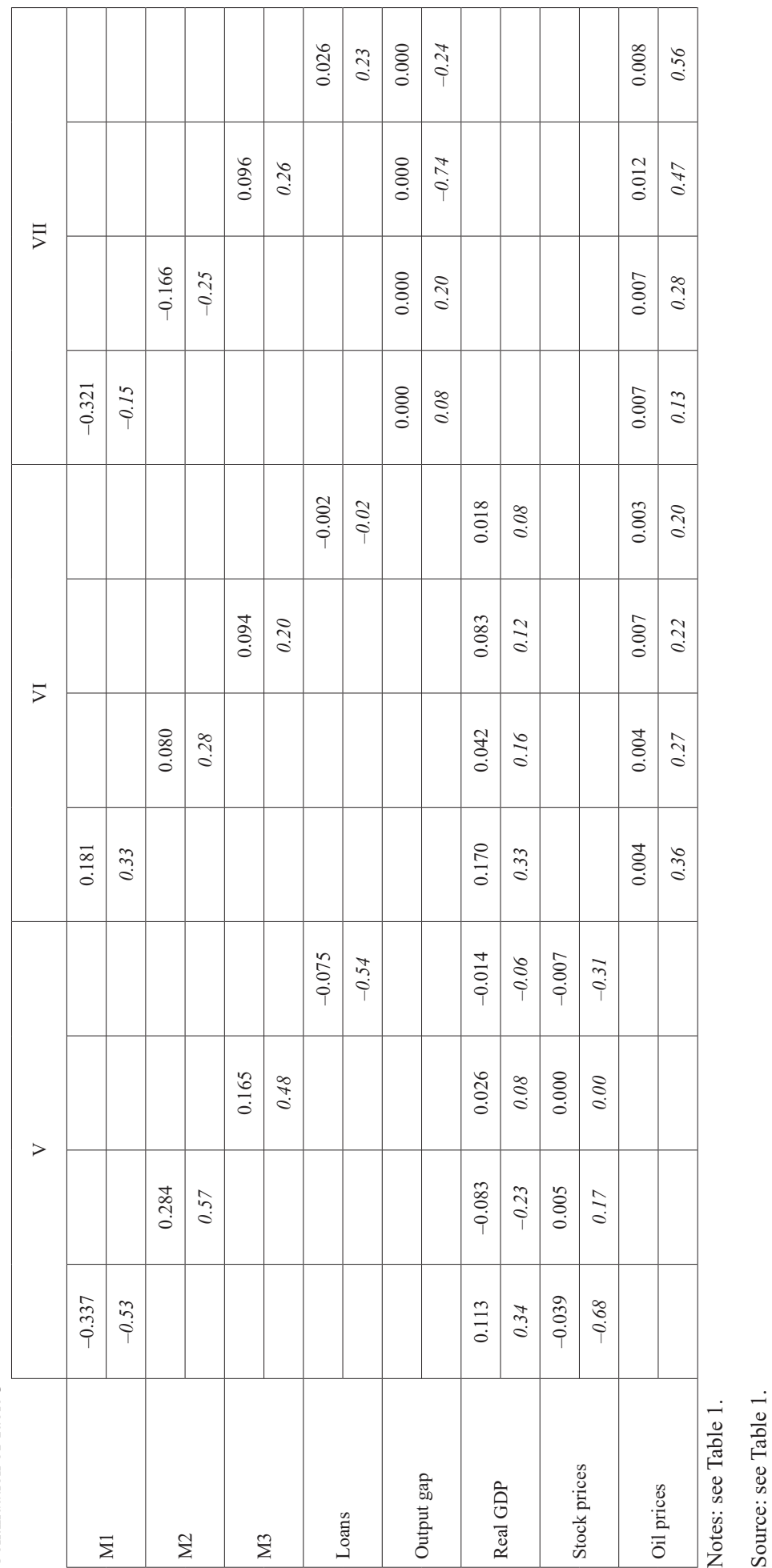




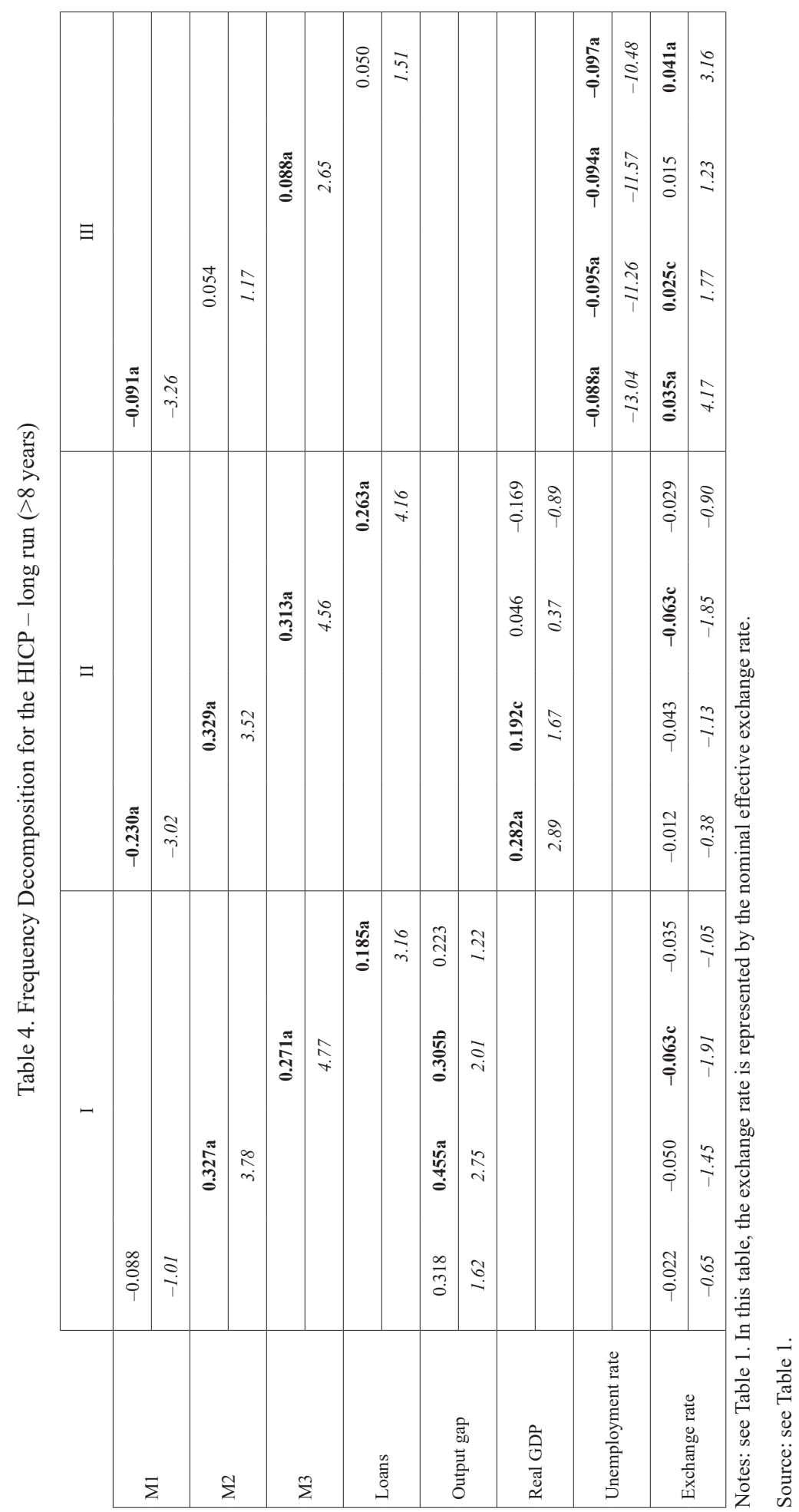




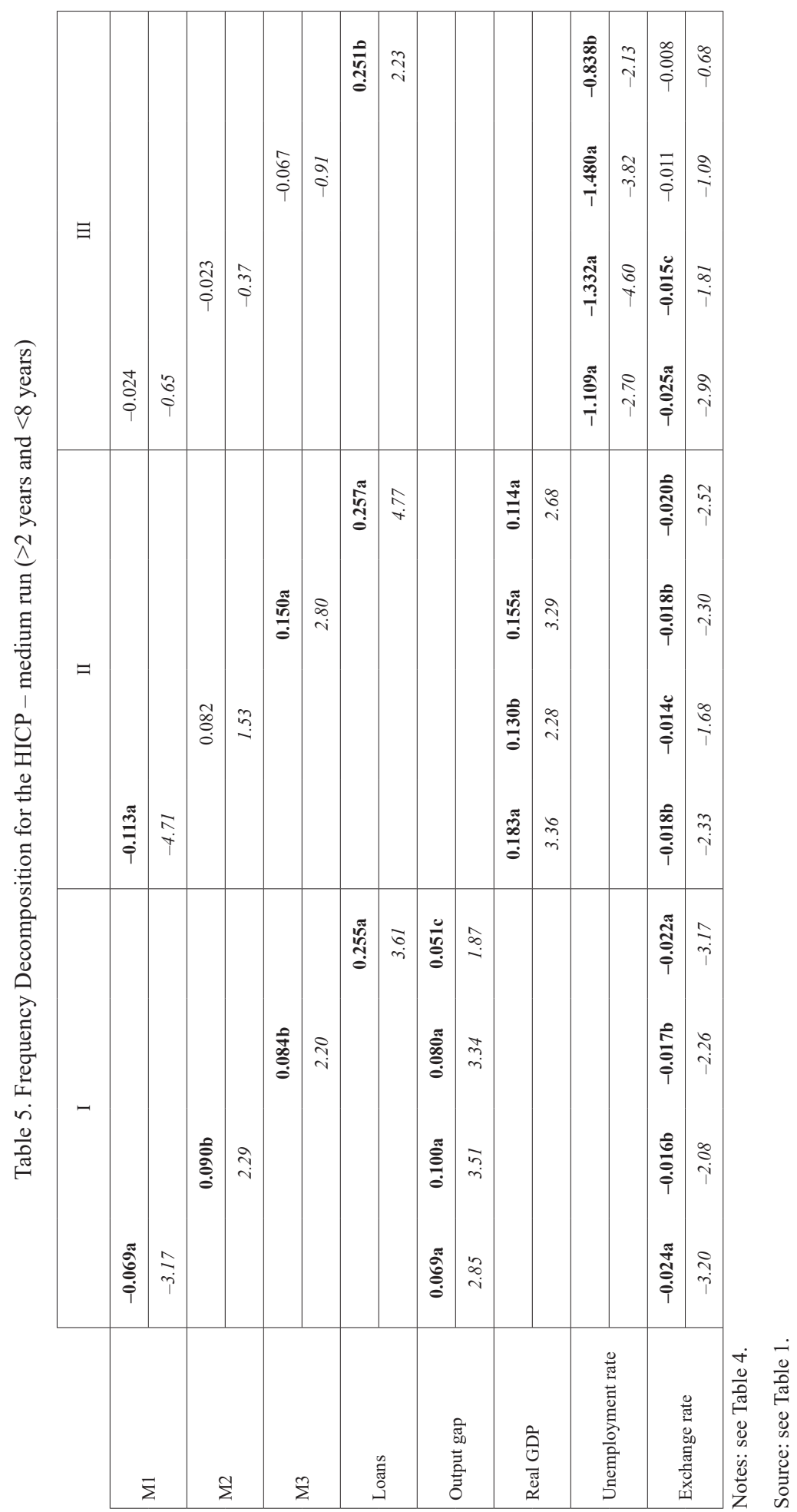




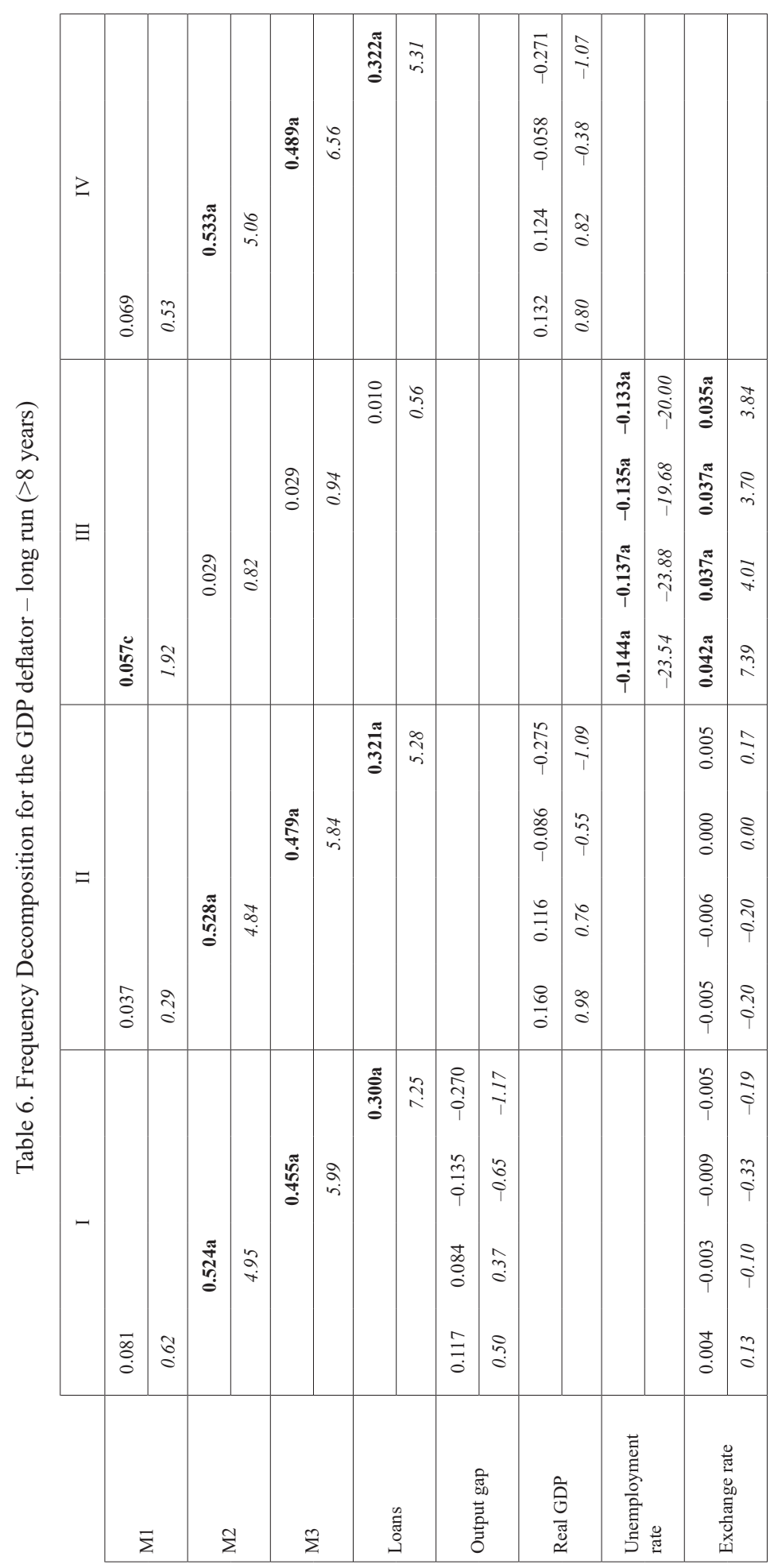




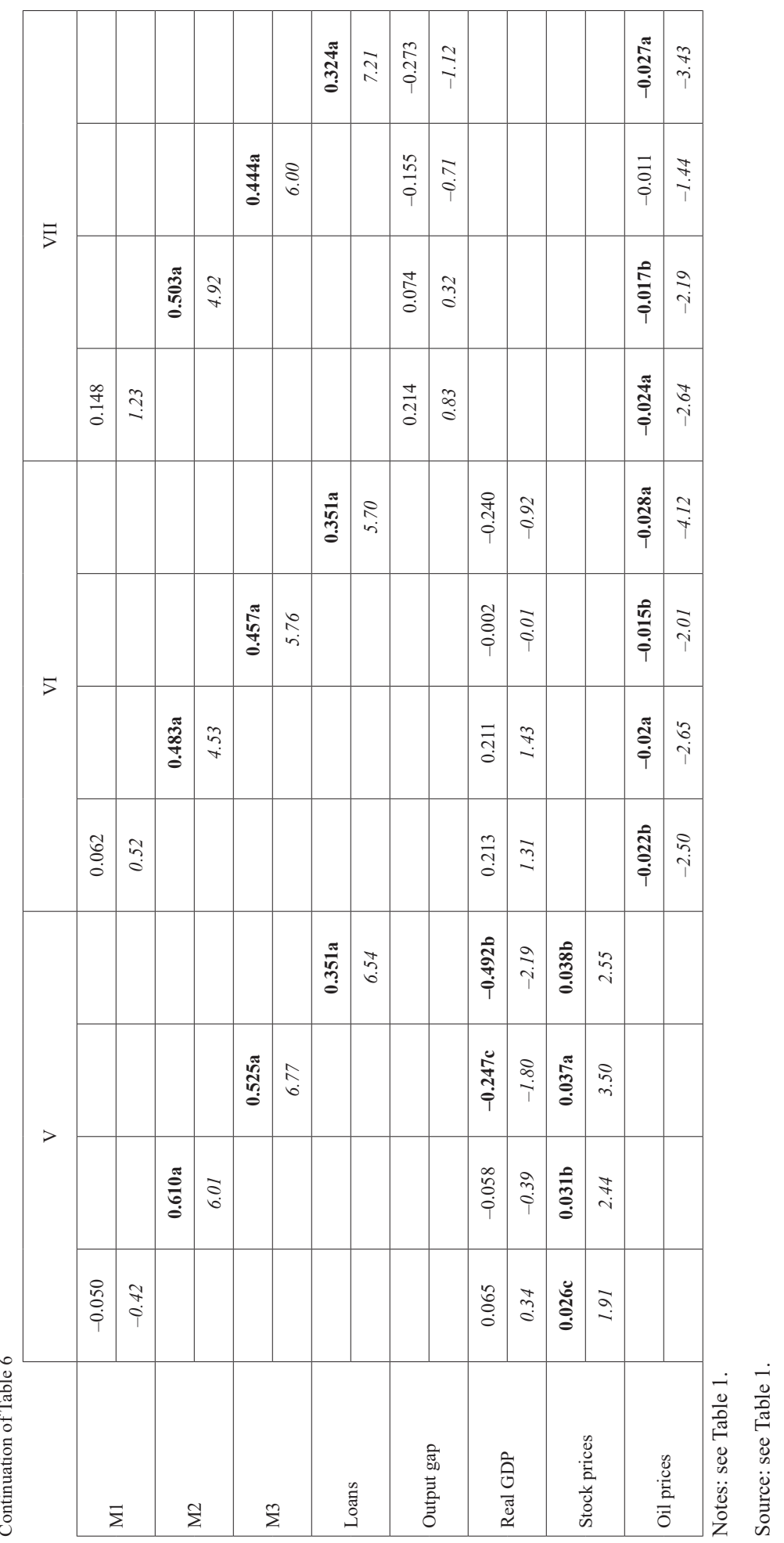




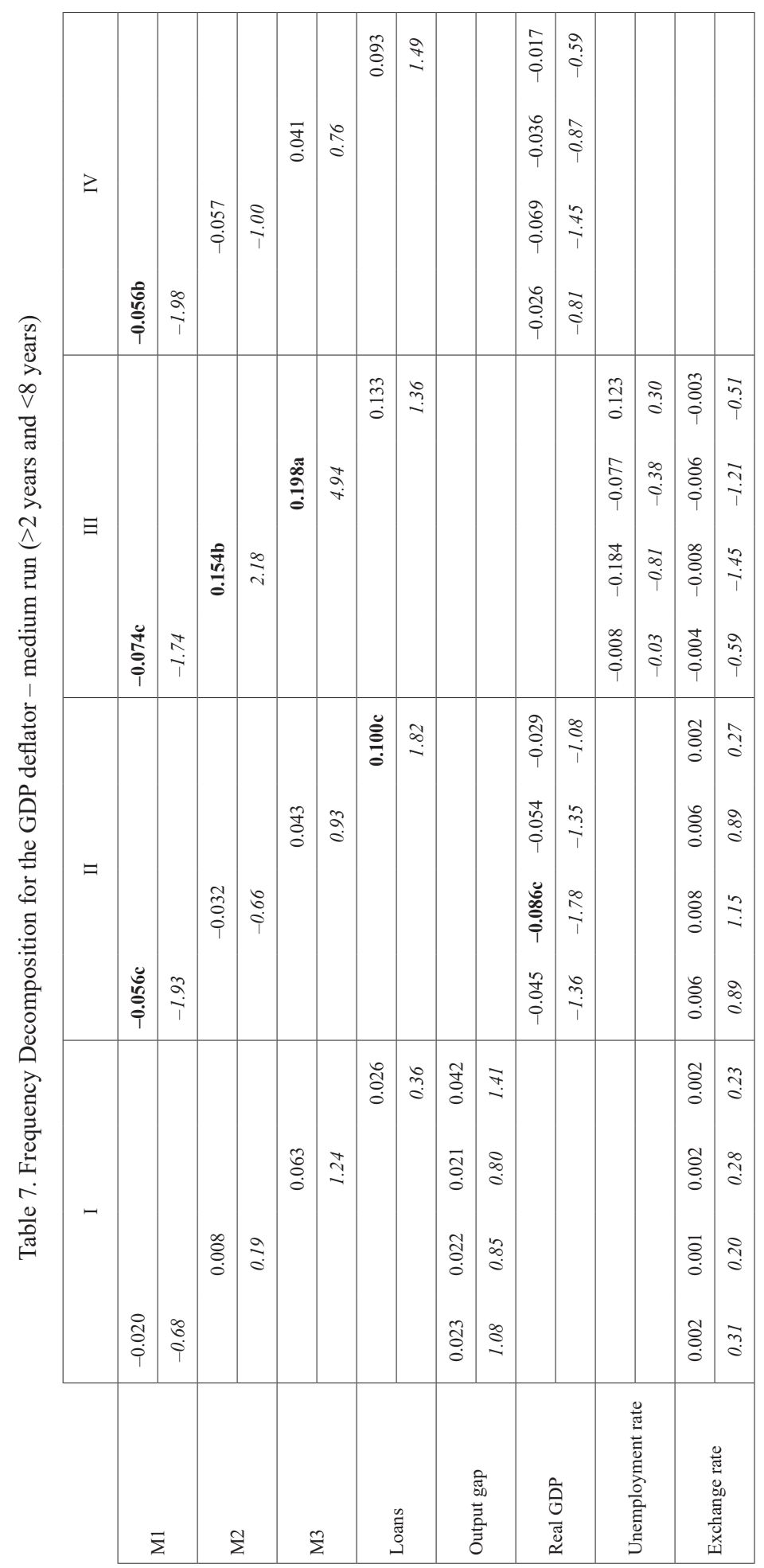




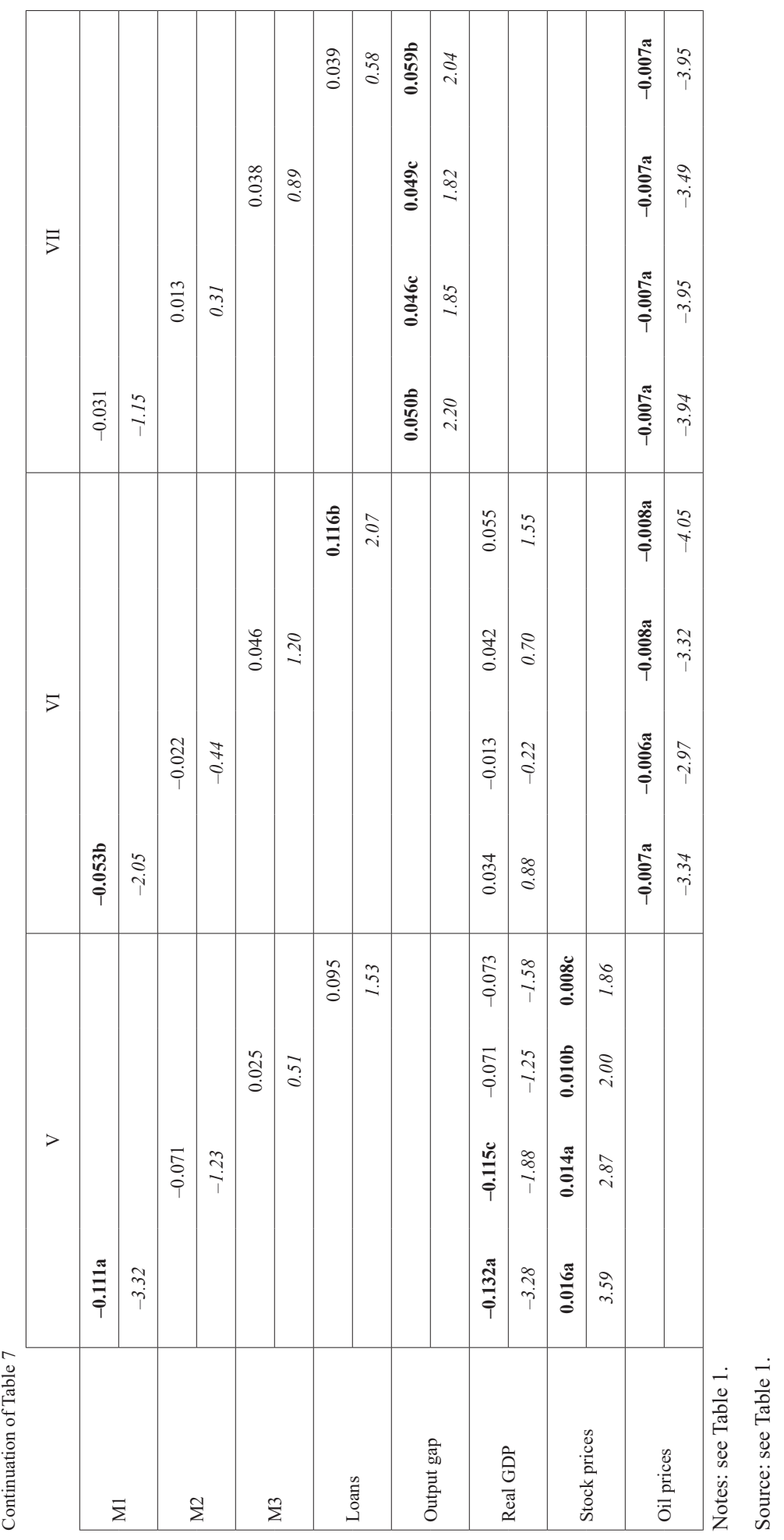




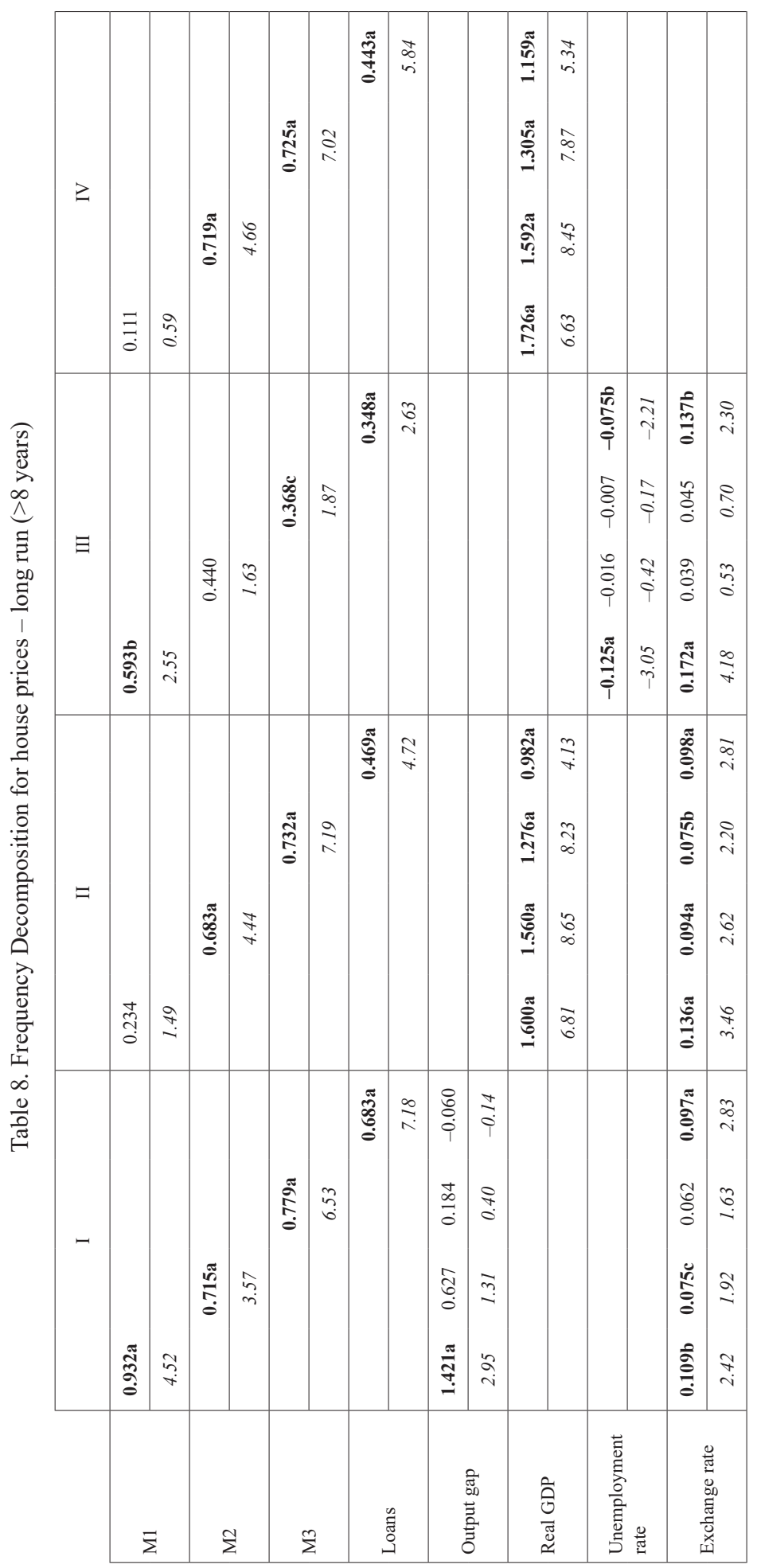




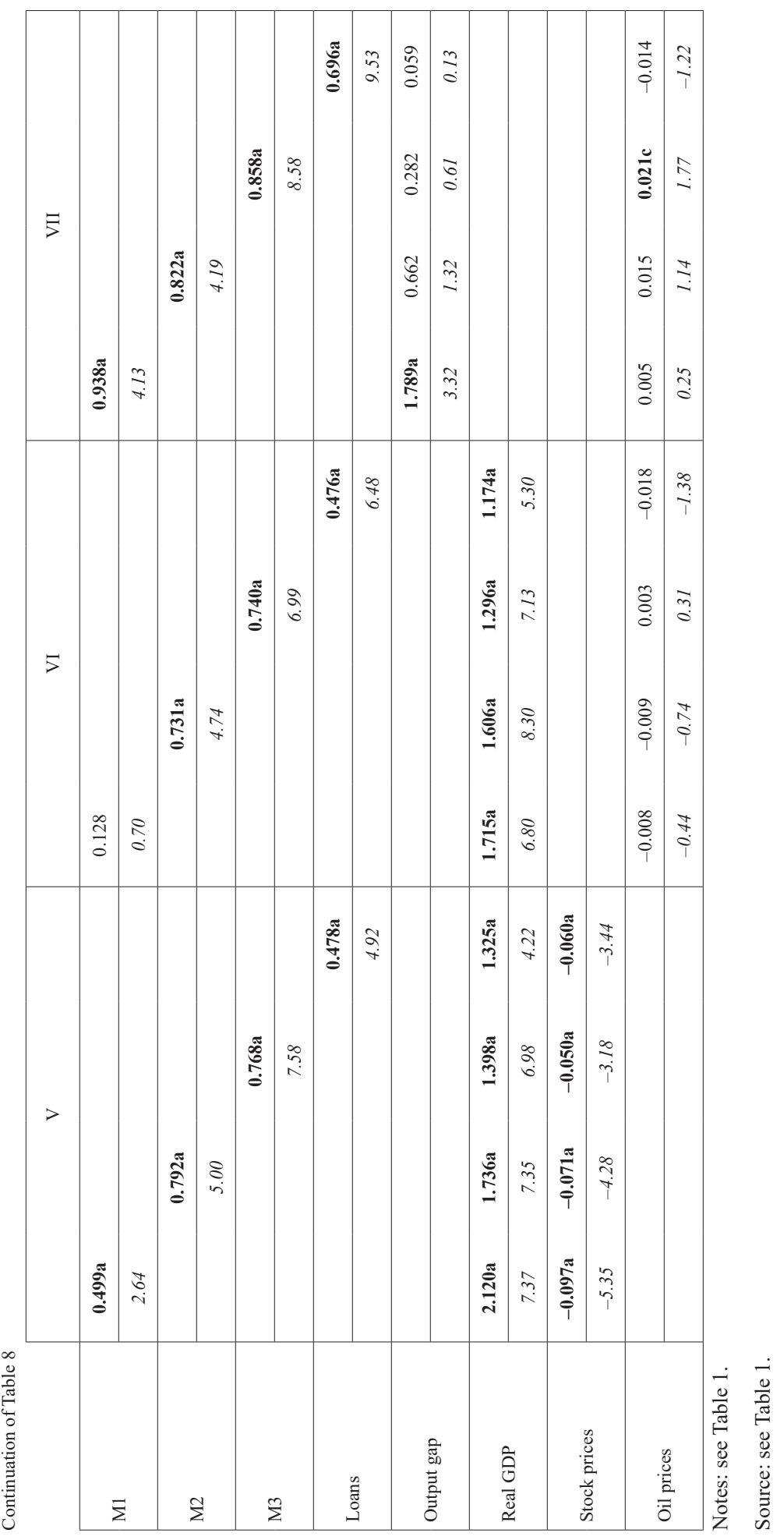




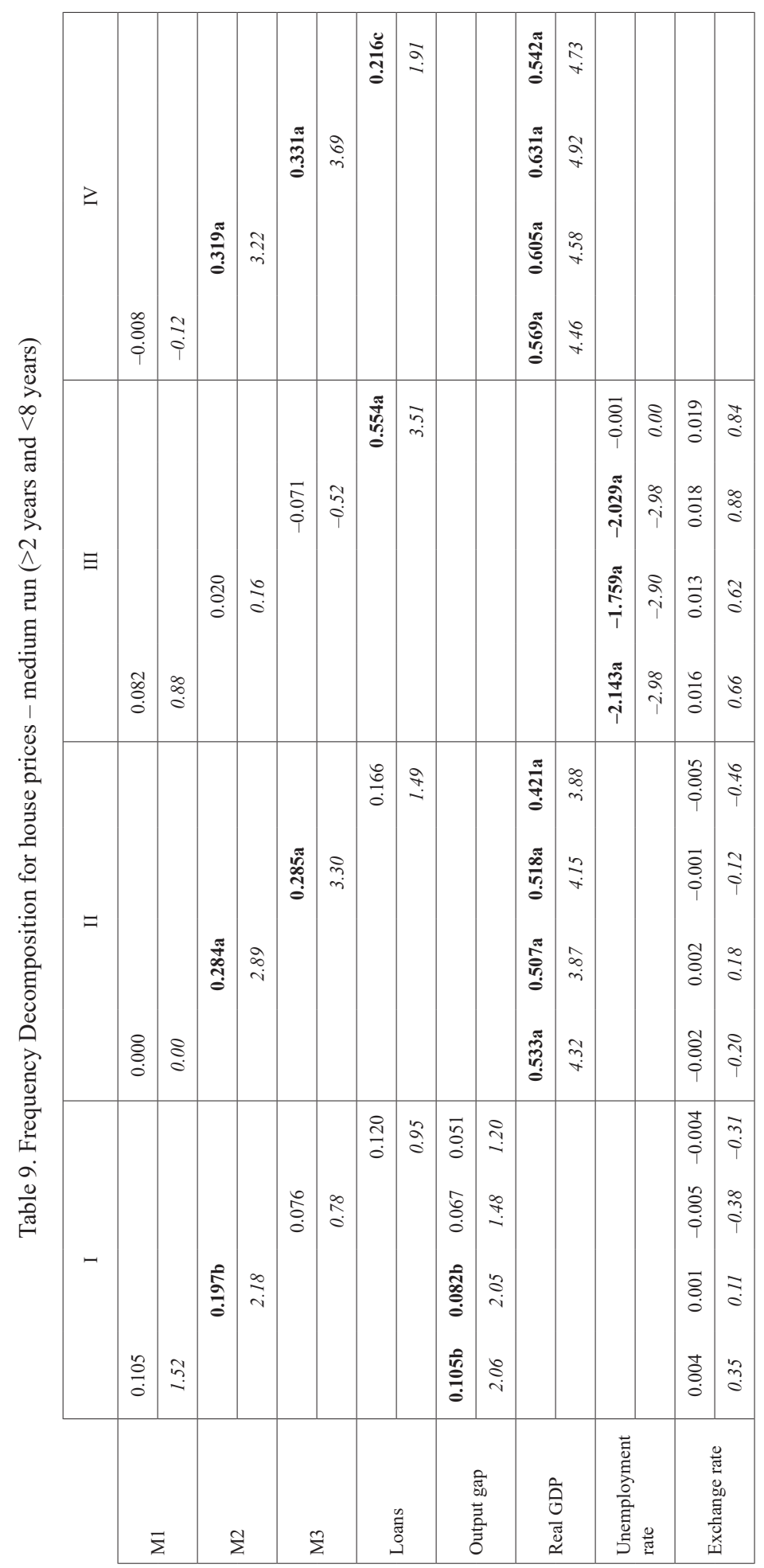




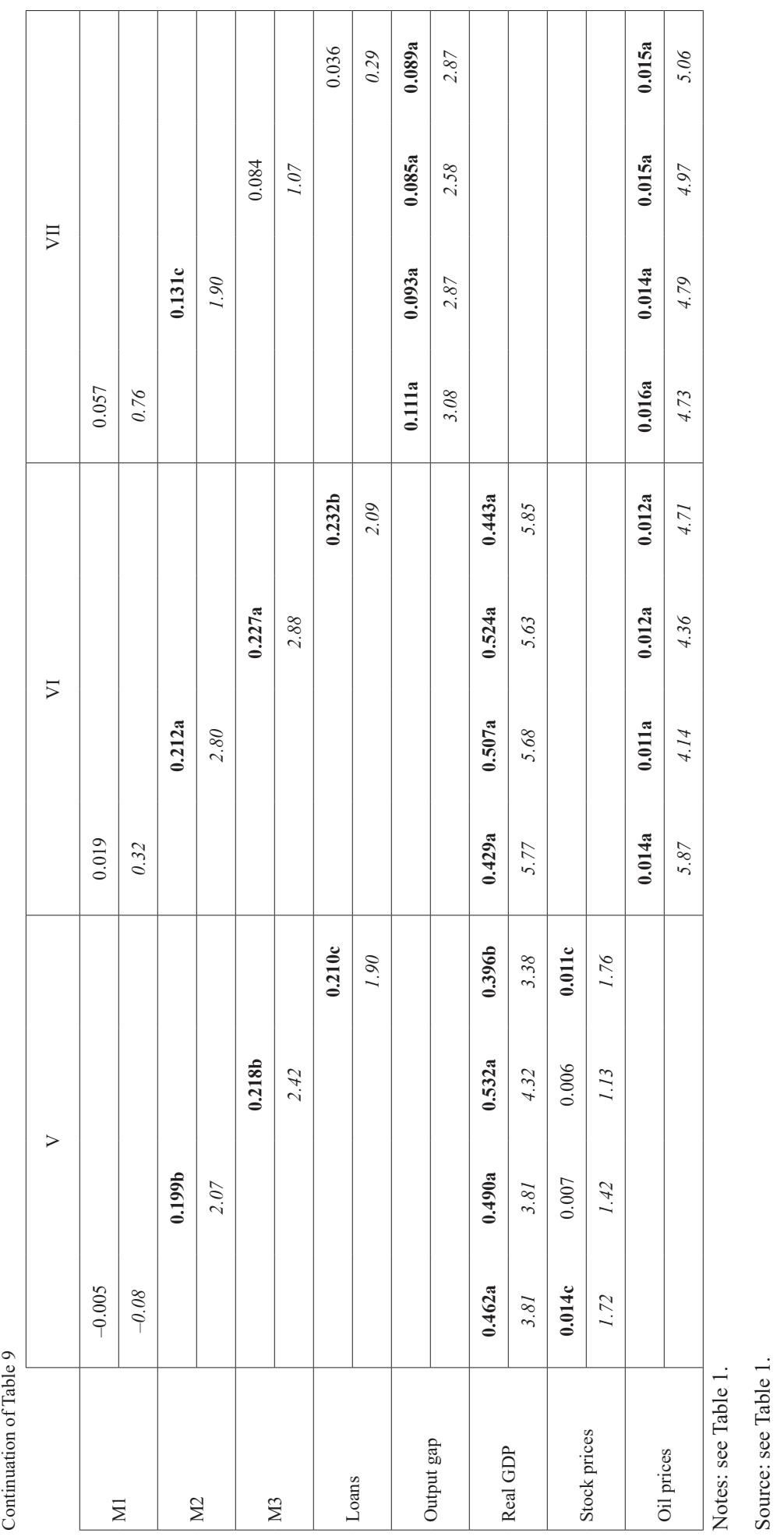




\section{References}

Andersson, F.N.G. (2008). Long run inflation indicators - Why the ECB got it right. Working Paper 2008-2017, Department of Economics, Lund University.

Andersson, F.N.G. (2011). Monetary policy, asset price inflation and consumer price inflation. Economics Bulletin, 31 (1), 759-770.

Anderson, R.G., Bordo, M., Duca, J.V. (2017). Money and velocity during financial crisis: from the Great Depression to the Great Recession. Journal of Economic Dynamics and Control, 81, 32-49.

Assenmacher-Wesche, K., Gerlach, S. (2006a). Interpreting euro area inflation at high and low frequency. Centre for Economic Policy Research Discussion Paper 5632, April.

Assenmacher-Wesche, K., Gerlach, S. (2006b). Understanding the link between money growth and inflation in the euro area. Centre for Economic Policy Research Discussion Paper 5683, May.

Assenmacher-Wesche, K., Gerlach, S. (2006c). Money growth, output gaps and inflation at low and high frequency: spectral estimates for Switzerland. Centre for Economic Research Discussion Paper 5723, June.

Baxter, M., King, R.G. (1999). Measuring business cycles: approximate band-pass filters for economic time series. The Review of Economics and Statistics, 81 (4), 575-593.

Benati, L. (2009). Long-run evidence on money growth and inflation. ECB Working Paper 1027.

Bernanke, B.S. (1993). Credit in the macroeconomy. Quarterly Review of the Federal Reserve Bank of New York, Spring, 50-70.

Brand, C., Gerdesmeier, D., Roffia, B. (2002). Estimating the trend of M3 income velocity underlying the reference value for monetary growth. ECB Occasional Paper 2.

Christiano, L.J., Fitzgerald, T.J. (2003). The band pass filter. International Economic Review, $44(2), 435-465$.

European Central Bank (1998). The quantitative reference value for monetary growth. ECB Press Release, 1 December.

European Central Bank (1999a). The stability-oriented monetary policy strategy of the Eurosystem. Monthly Bulletin, January, 39-50.

European Central Bank (1999b). Euro area monetary aggregates and their role in the Eurosystem's monetary policy strategy. Monthly Bulletin, February, 29-46.

European Central Bank (2001a). Monetary analysis: tools and applications. European Central Bank, Frankfurt.

European Central Bank (2001b). Framework and tools of monetary analysis. Monthly Bulletin, May, 41-58. 
European Central Bank (2001c). Estimates of the nominal and real money gap in the euro area. Monthly Bulletin, June, 9-10.

European Central Bank (2003). The outcome of the ECB's evaluation of its monetary policy strategy. Monthly Bulletin, June, 79-92.

European Central Bank (2004). The link between asset prices and monetary developments. Monthly Bulletin, September, 20-21.

European Central Bank (2008). The external dimension of monetary analysis. Monthly Bulletin, August, 71-84.

European Central Bank (2010a). Asset price bubbles and monetary policy revisited. Monthly Bulletin, November, 71-83.

European Central Bank (2010b). Enhancing monetary analysis. Monthly Bulletin, November, 85-99.

Engle, R.F. (1974). Bandspectrum regression. International Economic Review, 15 (1), 1-11.

Friedman, M., Schwartz, A.J. (1963). A monetary history of the United States, 1867-1960. Princeton University Press.

Gallegati, M., Gallegati, M., Ramsey, J.B., Semmler, W. (2017). Long waves in prices: new evidence from Wavelet analysis. Cliometrica, 11, 127-151.

Gerdesmeier, D., Reimers, H.-E, Roffia, B. (2016). Asset prices and consumer prices: exploring the linkages. Applied Economics Quarterly, 62 (3), 169-186.

Gerdesmeier, D., Reimers, H.-E, Roffia, B. (2018). Unravelling the secrets of euro area inflation: a frequency decomposition approach. Wismarer Diskussionspapiere, 6.

Gerlach, S. (2003). The ECB's two pillars. Centre for Economic Policy Research Discussion Paper 3689.

Gerlach, S. (2004). The two pillars of the European Central Bank. Economic Policy, 40, 389439.

Gerlach, S., Svensson, L. (2003). Money and inflation in the euro area: a case for monetary indicators? Journal of Monetary Economics, 50, 649-672.

Hansen, L.P. (1982). Large sample properties of Generalized Method of Moments estimators. Econometrica, 50 (4), 1029-1054.

Haug, A.A., Dewald, W.G. (2012). Money, Output and Inflation in the Longer Term: Major Industrial Countries, 1880-2001. Economic Inquiry, 50 (3),773-787.

Hevia, C., Nicolini, J.P. (2017). Monitoring money for price stability. Federal Reserve Bank of Minneapolis, Working Paper 744.

IMF (2018). House price synchronization: what role for financial factors, Chapter 3, Global Financial Stability Report. April, Washington D.C. 
Lucas, R.E., Nicolini, J.P. (2015). On the stability of money demand. Journal of Monetary Economics, 73, 48-65.

Moulton, J.G., Wentland, S.A. (2017). Monetary policy and the housing market: evidence from national microdata. Discussion Paper Bureau of Economic Analysis, U.S Department of Commerce.

Nelson, E. (2008). Why money growth determines inflation in the long run: answering the Woodford critique. Journal of Money, Credit and Banking, 40, 1791-1814.

Neumann, M.J.M., Greiber, C. (2004). Inflation and core money growth in the euro area. Deutsche Bundesbank Discussion Paper 36.

Nocera, A., Roma, M. (2017). House prices and monetary policy in the euro area: evidence from structural VARs. European Central Bank Working Paper 2073.

Rua, A. (2011). Money growth and inflation in the euro area: a time-frequent view. Banco de Portugal Working Paper 22/2011. 